\title{
The HIF1 $A$ functional genetic polymorphism at locus +1772 associates with progression to metastatic prostate cancer and refractoriness to hormonal castration
}

\author{
Avelino Fraga ${ }^{\mathrm{a}, \mathrm{b}, *}$, Ricardo Ribeiro ${ }^{\mathrm{c}, \mathrm{d}, \mathrm{e}, \mathrm{f}}$, Paulo Príncipe ${ }^{\mathrm{a}}$, Carlos Lobato ${ }^{\mathrm{g}}$, \\ Francisco Pina $^{\mathrm{h}}$, Joaquina Maurício ${ }^{\mathrm{i}}$, Cátia Monteiro ${ }^{\mathrm{c}, \mathrm{e}}$, Hugo Sousa ${ }^{\mathrm{c}}$, \\ F. Calais da Silva ${ }^{j}$, Carlos Lopes ${ }^{\mathrm{b}}$, Rui Medeiros ${ }^{\mathrm{b}, \mathrm{c}, \mathrm{e}}$
}

\footnotetext{
${ }^{a}$ Urology Department, Sto António Hospital, Porto Hospital Centre, Porto, Portugal

${ }^{\mathrm{b}}$ ICBAS, Abel Salazar Biomedical Sciences Institute, University of Porto, Porto, Portugal

${ }^{\mathrm{c}}$ Molecular Oncology Group-CI, Portuguese Institute of Oncology, Porto, Portugal

${ }^{\mathrm{d}}$ Genetics Laboratory, Faculty of Medicine, University of Lisbon, Lisboa, Portugal

${ }^{\mathrm{e}}$ LPCC - Portuguese League Against Cancer (NRNorte), Porto, Portugal

${ }^{\mathrm{f}}$ Instituto Rocha Cabral, Lisboa, Portugal

${ }^{\mathrm{g}}$ Urology Department, D. Pedro V Military Hospital, Porto, Portugal

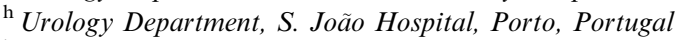

${ }^{\mathrm{i}}$ Medical Oncology Department, Portuguese Institute of Oncology, Porto, Portugal

${ }^{j}$ Urology Department, Central Lisbon Hospital Centre, Lisboa, Portugal
}

Available online 30 September 2013

\section{KEYWORDS \\ Androgen deprivation therapy \\ Hypoxia inducible factor \\ 1 alpha \\ Metastasis \\ Prostate cancer \\ Single nucleotide \\ polymorphism}

\begin{abstract}
The hypoxia inducible factor 1 alpha (HIF1a) is a key regulator of tumour cell response to hypoxia, orchestrating mechanisms known to be involved in cancer aggressiveness and metastatic behaviour. In this study we sought to evaluate the association of a functional genetic polymorphism in $H I F 1 A$ with overall and metastatic prostate cancer (PCa) risk and with response to androgen deprivation therapy (ADT).

The HIFlA $+1772 \mathrm{C}>\mathrm{T}$ (rs11549465) polymorphism was genotyped, using DNA isolated from peripheral blood, in 1490 male subjects (754 with prostate cancer and 736 controls cancer-free) through Real-Time PCR. A nested group of cancer patients who were eligible for androgen deprivation therapy was followed up. Univariate and multivariate models were used to analyse the response to hormonal treatment and the risk for developing distant metastasis. Age-adjusted odds ratios were calculated to evaluate prostate cancer risk.

Our results showed that patients under ADT carrying the HIF1A $+1772 \mathrm{~T}$-allele have increased risk for developing distant metastasis (OR, 2.0; 95\% CI, 1.1-3.9) and an independent 6-fold increased risk for resistance to ADT after multivariate analysis (OR, 6.0; 95\% CI, 2.2 16.8). This polymorphism was not associated with increased risk for being diagnosed with prostate cancer (OR, 0.9; 95\% CI, 0.7-1.2).
\end{abstract}

\footnotetext{
* Corresponding author. Address: Porto Hospital Centre, St. António Hospital, Urology Department, Largo Prof. Abel Salazar, 4000-001 Porto, Portugal. Tel.: +351 222077507; fax: +351 220900642.

E-mail address: avfraga@gmail.com (A. Fraga).
} 
The HIFlA +1772 genetic polymorphism predicts a more aggressive prostate cancer behaviour, supporting the involvement of HIFla in prostate cancer biological progression and ADT resistance. Molecular profiles using hypoxia markers may help predict clinically relevant prostate cancer and response to ADT.

(c) 2013 Elsevier Ltd. All rights reserved.

\section{Introduction}

Prostate cancer (PCa) remains a major public health concern because it is the most common malignant neoplasia and the second leading cause of cancer death in men [1].

Clinically, it is a heterogeneous disease, with aggressiveness risk differing greatly among individuals despite similar clinical and pathological characteristics. Currently, only incipient but scarce markers help to predict whether PCa will be an aggressive, fast growing disease or an indolent slow growing type of cancer [2]. Therefore, new strategies to help clinicians distinguish between lethal and indolent prostate cancer are needed. Recent findings indicate that genetic variants may predispose to more aggressive prostate cancer [3-5], which is supported by epidemiological studies that propose genetic background influences cancer prognosis [6-8]. Recent genome-wide association studies (GWAS) revealed numerous genetic variants associated with prostate cancer risk, although only little discriminatory ability was shown for fatal forms of the disease [9].

Intratumoural hypoxia is a hallmark of solid neoplasias. It is well established that hypoxic tumoural microenvironment initiates multiple cellular responses, ultimately resulting in cancer progression [10,11]. The hypoxia inducible factor 1 alpha (HIF1a) is a transcription factor coded by the $H I F 1 A$ gene that regulates cellular response to hypoxia $[12,13]$, inducing cancer progression through activation of many genes involved in regulatory cancer biology (angiogenesis, cell metabolism, cell survival, and epithelial-to-mesenchymal transition) [14]. The HIFlA gene harbours several SNPs, including a C-to-T substitution at locus +1772 that result in aminoacid modification (proline by serine). Previous in vitro studies showed higher transcriptional activity of the variant allele under both normoxic and hypoxic conditions [12,14], whereas additional research associated this SNP with increased tumour microvessel density [12,14,15].

Recent studies yielded conflicting results regarding the involvement of $H I F 1 A+1772 \mathrm{C}>\mathrm{T}$ genetic polymorphism in cancer, albeit a significant positive association remained after meta-analysis in Caucasian women specific cancers $[16,17]$. In prostate cancer, the few studies were conducted in distinct ethnic populations and clinicopathological characteristics leading to conflicting results $[16,18,19]$. Furthermore, the association of $H I F 1 A$ $+1772 \mathrm{C}>\mathrm{T}$ SNP with prostate cancer progression, metastasis and refractoriness to androgen deprivation therapy (ADT) merits further evaluation in larger series of patients. In the present study we sought to analyse the association of the functional SNP $+1772 \mathrm{C}>\mathrm{T}$ in $H I F 1 A$ with PCa using prostatic biopsy-proven controls, and to predict the response to treatment in men receiving ADT.

\section{Patients and methods}

\subsection{Patients}

Subjects with histological confirmation, whether on biopsy or surgical specimen, of prostate cancer $(n=754)$ or absence of malignancy $(n=736)$ were included in a case-control study. Patients were recruited from five Hospitals in Portugal between 1990 and 2009: Portuguese Institute of Oncology - Porto Centre, S. João Hospital, Porto Military Hospital, Porto Hospital Centre, and Central Lisbon Hospital Centre. The study was approved by hospital's research ethics committees and consent obtained from participants.

The non-PCa control group comprises men referred for prostate biopsy (8-13 cores) on the basis of abnormal digital rectal examination and/or single baseline PSA levels over $2.5 \mathrm{ng} / \mathrm{ml}$, but with normal or benign prostatic histology. Subjects without malignancy at biopsy (BPH or chronic prostatitis) were considered controls since (1) diagnosis was contemporary, (2) were age matched with elderly cancer patients, (3) all were submitted to digital rectal examination, PSA estimate and prostatic biopsy, making remote the possibility of crossover, (4) most men have benign diseases of the prostate by the 7 th -8 th decades of life, making it normal in men of that age, (5) bias would be expectable if only men without prostatic disease were eligible, because of the much younger range of ages. Patients with highgrade prostatic intraepithelial neoplasia or a biopsy suspicious of cancer were excluded.

A nested sample of subjects from the group of $\mathrm{PCa}$ patients (those eligible for androgen deprivation therapy, ADT, $(n=429)$ was followed up for several years. These patients were submitted to orchiectomy or luteinising hormone releasing hormone agonist (LHRHa) (with or without anti-androgen) immediately after diagnosis or after relapsing from surgery/radiotherapy. Resistance to ADT was defined as the time from ADT initiation to two consecutive rises of PSA greater than the PSA nadir or progression of bone lesions $[20,21]$. 
The time intervals between visits to the clinic were those routinely in use and determined by international, namely European, guidelines [20,22]. Information was collected through chart review.

\subsection{Genotyping}

A venous blood sample $(6 \mathrm{ml})$ was obtained by forearm venipuncture and the white cell fraction used to extract DNA (QIAmp DNA Blood Mini Kit, Qiagen). Blood samples for genetic analysis were collected independent of treatment initiation. The HIFlA +1772 $\mathrm{C}>\mathrm{T}$ (rs11549465) genetic polymorphism was genotyped by Real-Time PCR using a pre-designed validated Taqman assay (Applied Biosystems). Procedures implemented for quality control included double sampling in about $5 \%$ of samples and the use of negative controls in every run.

\subsection{Statistical analysis}

The Kolmogorov-Smirnov test was used to assess departure from normality of continuous variables, while medians and interquartile ranges were used as descriptive statistics. The Mean differences between groups for data not normally distributed was compared by Mann-Whitney or Kruskal-Wallis tests. The departure from Hardy-Weinberg equilibrium for HIF1A +1772 $\mathrm{C}>\mathrm{T}$ polymorphism in the non-prostate cancer group was tested by Pearson's chi-square.

Unconditional logistic regression was used to estimate age-adjusted odds ratios (aORs) and 95\% confidence intervals $(95 \% \mathrm{CIs})$ for the associations between the polymorphism and development of prostate cancer based on additive, recessive and dominant genetic models (additive, $\mathrm{CC}$ versus $\mathrm{Ct}$ versus $\mathrm{tt}$, and based on the minor allele: dominant, $\mathrm{CC}$ versus $\mathrm{Ct}+\mathrm{tt}$; recessive, $\mathrm{CC}+\mathrm{Ct}$ versus $\mathrm{tt})$. We examined the association of HIFlA $+1772 \mathrm{C}>\mathrm{T}$ genetic polymorphism with overall prostate cancer and restricted to high-grade prostate cancer (combined Gleason score $\geqslant 7$ ) in comparison with controls non-cancers.

Serum PSA at diagnosis was stratified according to a $20 \mathrm{ng} / \mathrm{ml}$ cutoff, the combined Gleason score was stratified into two groups $(<7$ versus $\geqslant 7)$, whereas clinical stage was further stratified as localised (T1-T2) or advanced (defined as a tumour invading and extending beyond the prostate capsule and/or extending into adjacent tissue, involving regional lymph nodes and/or distant metastatic sites). The time-to-resistance to ADT was calculated as the interval (in months) since the beginning of ADT until the date of resistance to ADT or last visit.

Empirical analyses were conducted to determine covariates for multivariate models. For time-to-event analyses, age-adjusted Cox regression models were used to assess risk of ADT resistance, whereas age-adjusted logistic regression models were used to evaluate the risk for metastasis. Then, multivariate analysis included relevant clinical variables from empirical evaluation and genetic models. A multivariate Cox proportional hazards model was derived to identify the independent predictive risks for biochemical progression under hormonal castration, while a multivariate logistic regression model was performed to evaluate clinical and genetic predictive factors for prostate cancer metastasis. Statistical analyses were done using STATA version 10.0 (StataCorp, College Station, Texas).

\section{Results}

One-thousand four hundred ninety individuals were included in this study, 736 cancer-free controls and 754 with a positive biopsy for prostate cancer (median age, 66.8 and 68.0 years old, respectively, $p=0.001$ ). Biopsy findings in the control cancer-free group revealed normal histology $(10.9 \%)$, benign prostatic hyperplasia $(33.4 \%)$, chronic prostatitis $(55.2 \%)$ and atrophy $(0.5 \%)$. As expected, PCa patients presented significantly higher serum PSA levels at diagnosis $(p<0.0001)$.

HIF1A +1772 (rs11549465) genotype distribution by group and risk analysis is shown in Table 1. Both additive and dominant genetic models were not associated with prostate cancer risk or high grade disease. The distribution of HIF1A $+1772 \mathrm{C}>\mathrm{T}$ genotypes among the non-cancer control subjects were in agreement with Wardy-Weinberg equilibrium ( $p=0.988$ ). Furthermore, we found that this SNP was not associated to earlier onset of disease, using Kaplan-Meier plots and functions (data not shown).

In the group of prostate cancer patients, analyses of the association between $H I F 1 A+1772$ genetic variants and patient's clinicopathological characteristics showed over-representation of T-allele in the group of patients not treated with definitive therapy $(p=0.05)$ and who developed metastasis at any time during the course of malignant disease (Table 2).

From the group of 754 patients with prostate cancer, 429 were eligible for androgen deprivation therapy, either due to advanced disease at diagnosis or due to disease progression. The clinicopathological characteristics of this nested group are shown in Table 3. From the group of patients on ADT, 194 (45.2\%) developed resistance to hormonal therapy. The median $(95 \% \mathrm{CI})$ followup time was 91.8 (79.8-103.7) months.

Univariate age-adjusted empirical time-to-ADT resistance analysis on clinical covariates showed that Gleason grade $\geqslant 7$ (HR, 2.8; 95\%CI, 2.0-4.1), advanced clinical stage (HR, 3.7; 95\% CI, 2.5-5.3), definitive treatment (HR, 0.6; 95\%CI, 0.4-0.8), PSA $\geqslant 20 \mathrm{ng} / \mathrm{ml}(\mathrm{HR}$, $1.9 ; 95 \% \mathrm{CI}, 1.5-2.6)$ and presence of metastasis at ADT initiation (HR, 2.9; 95\%CI, 2.1-3.9) were all 
Table 1

HIF1A +1772 genotype distribution and risk for prostate cancer.

\begin{tabular}{|c|c|c|c|c|c|}
\hline \multirow[b]{3}{*}{$H I F 1 A$ genotypes } & \multirow{3}{*}{$\begin{array}{l}\text { Control } \\
N\end{array}$} & \multicolumn{4}{|c|}{ Prostate cancer } \\
\hline & & \multicolumn{2}{|l|}{ All } & \multicolumn{2}{|c|}{ High-grade (Gleason $\geqslant 7$ ) } \\
\hline & & $N$ & $\mathrm{aOR}(95 \% \mathrm{CI})$ & $N$ & $\mathrm{aOR}(95 \% \mathrm{CI})$ \\
\hline $\begin{array}{l}\text { Additive model } \\
\text { CC } \\
\text { CT } \\
\text { TT }\end{array}$ & $\begin{array}{l}566 \\
156 \\
14\end{array}$ & $\begin{array}{l}579 \\
164 \\
11\end{array}$ & $\begin{array}{l}\text { Referent } \\
1.0(0.8-1.3) \\
0.9(0.4-2.1)\end{array}$ & $\begin{array}{l}333 \\
83 \\
7\end{array}$ & $\begin{array}{l}\text { Referent } \\
0.9(0.7-1.2) \\
1.0(0.4-2.5)\end{array}$ \\
\hline $\begin{array}{l}\text { Dominant model } \\
\text { CC } \\
\mathrm{T} \text { carriers }\end{array}$ & $\begin{array}{l}566 \\
170\end{array}$ & $\begin{array}{l}579 \\
175\end{array}$ & $\begin{array}{l}\text { Referent } \\
1.0(0.8-1.3)\end{array}$ & $\begin{array}{l}333 \\
90\end{array}$ & $\begin{array}{l}\text { Referent } \\
0.9(0.7-1.2)\end{array}$ \\
\hline
\end{tabular}

aOR $(95 \% \mathrm{CI})$, age-adjusted odds ratios and the respective $95 \%$ confidence intervals.

Table 2

Genotype distribution in PCa subjects $(n=754)$ according to clinicopathological characteristics.

\begin{tabular}{|c|c|c|c|c|}
\hline & \multicolumn{3}{|c|}{ HIF1A +1772 C $>$ T genotypes } & \multirow[b]{2}{*}{$p$} \\
\hline & $\mathrm{CC}(n=579)$ & $\mathrm{CT}(n=164)$ & $\mathrm{TT}(n=11)$ & \\
\hline \multicolumn{5}{|l|}{ Definitive therapy } \\
\hline No & $228(75.0)$ & $69(22.7)$ & $7(2.3)$ & \\
\hline Yes & $281(78.5)$ & $76(21.2)$ & $1(0.3)$ & $0.05^{*}$ \\
\hline \multicolumn{5}{|l|}{ Clinical stage } \\
\hline Localised & $262(78.9)$ & $67(20.2)$ & $3(0.9)$ & \\
\hline Advanced & $222(76.0)$ & $66(22.6)$ & $4(1.4)$ & $0.639^{*}$ \\
\hline \multicolumn{5}{|l|}{ Gleason score } \\
\hline$<7$ & $177(75.0)$ & $56(23.7)$ & $3(1.3)$ & \\
\hline$\geqslant 7$ & $333(78.7)$ & $83(19.6)$ & $7(1.7)$ & $0.443^{*}$ \\
\hline Tumour percent $\mathrm{a}^{\mathrm{a}}$ & $17.0(6.0-40.0)$ & $20.0(5.0-38.5)$ & $65.0(50.0-80.0)$ & $0.185^{* *}$ \\
\hline
\end{tabular}

significantly associated with resistance to ADT. The associations between HIFlA $+1772 \mathrm{C}>\mathrm{T}$ genotypes and the time-to-event age-adjusted univariate and multivariate analyses are shown in Table 4. Although we have not found association of $H I F 1 A+1772 \mathrm{C}>\mathrm{T}$ polymorphism with resistance to ADT on univariate analysis, in the recessive model the $\mathrm{T}$ homozygous genotype was associated with a 6-fold higher risk for developing resistance to ADT, after adjustment for relevant clinicopathological variables (Gleason grade, clinical stage, PSA $\geqslant 20 \mathrm{ng} / \mathrm{ml}$, definitive therapy and existence of metastases at the time of hormonal castration initiation) (Table 4). The risk of developing metastasis at any time during the course of disease in patients under ADT was significantly higher for T-allele carriers, still after adjustment for other clinical covariates (Gleason grade, clinical stage and PSA $\geqslant 20 \mathrm{ng} / \mathrm{ml}$ ) (Table 5).

\section{Discussion}

Hypoxia is a frequent event during prostate cancer progression, while the hypoxia-responsive gene HIFlA codes for a key transcription factor that has been proposed as a modulator of $\mathrm{PCa}$ initiation and progression [23-25]. We analysed a functional SNP $(+1772 \mathrm{C}>\mathrm{T})$ in the HIFlA gene in prostate cancer patients and controls and found lack of association, although a relatively large population with approximately 1500 men was analysed. Concordantly, two large case-control studies from the United States of America and China also observed no risk for having PCa in carriers of this polymorphism $[19,26]$, even though opposite results have been also reported [16,27]. The C-by-T substitution in the +1772 locus at the oxygen-dependent domain of the HIFIA gene results in a proline-to-serine substitution and was shown to stabilise HIFIA and enhance its activity as a transcription factor in both normoxia and hypoxia $[12,28]$. In agreement, albeit we hypothesised those carriers of $\mathrm{T}$ allele were more susceptible to have cancer, our data, together with other, suggest no influence in earlier stages of prostate cancer development. As PCa natural history usually reveals slow growing indolent tumours, the initial steps of carcinogenesis are not likely to be relevant sources of hypoxia, thereby inducing the 
Table 3

Clinicopathological characteristics features of the group of patients under that received ADT $(n=429)$.

\begin{tabular}{ll}
\hline & $n(\%)$ \\
\hline $\begin{array}{l}\text { Age at diagnosis, yrs } \\
\text { PSA at diagnosis, ng/ml }\end{array}$ & $70.0(64.9-75.4)$ \\
Median (IQR) & $19.0(8.9-51.6)$ \\
Gleason score & \\
$<7$ & $128(32.2)$ \\
$\geqslant 7$ & $269(67.8)$ \\
Clinical stage & \\
Localised & $156(38.7)$ \\
Advanced & $247(61.3)$ \\
Metastasis at ADT initiation & \\
No & $286(75.9)$ \\
Yes & $91(24.1)$ \\
Definitive therapy & \\
No & $299(69.7)$ \\
RP/RT & $130(30.3)$ \\
ADT pharmacological group & \\
aLHRH alone \\
aLHRH + antiandrogen
\end{tabular}

ADT, androgen deprivation therapy; aLHRH, luteinising hormone releasing hormone agonist; RP/RT, radical prostatectomy/radiotherapy; IQR, interquartile range.

activation of other than the HIF1a pathway. Actually, a previous report found that $H I F 1 A+1772 \mathrm{C}>\mathrm{T}$ genotypes were not correlated with HIF1a and VEGF expression in localised prostatic tumours [16]. However, HIFla overexpression has been reported in cancer precursor lesions, high grade prostate intraepithelial neoplasia, and early stage $\mathrm{PCa}$, compared with normal prostate epithelium [24].

Previous studies have shown overexpression of HIFla in many tumours with advanced grade, implying HIFla as an independent prognostic factor in cancer [15]. In addition, increasing evidence suggests that genetic markers may be independent predictors of outcome in PCa with various SNPs predicting decreased progression-free and overall survival [3-6]. Data presented here show that the homozygous $\mathrm{T}$ genotype $\mathrm{T}$ allele of HIF1 A $+1772 \mathrm{C}>\mathrm{T}$ is associated with increased relapsing after ADT, whereas the $\mathrm{T}$ allele is prone to higher risk for having distant metastasis, still after adjustment for empirical covariates (adjusted by Gleason grade, clinical stage and PSA $\geqslant 20 \mathrm{ng} / \mathrm{ml}$ for the risk of metastasis; and by Gleason grade, clinical stage, PSA $\geqslant 20 \mathrm{ng} / \mathrm{ml}$, definitive therapy and existence of metastases at the time of hormonal castration initiation for the risk of disease recurrence after ADT). While the recessive model (TT versus $\mathrm{CT} / \mathrm{CC}$ ) was significantly associated with resistance to ADT, the dominant (TT/ CT versus $\mathrm{CC}$ ) and additive models were significant for metastasis development under ADT. A recently published meta-analysis suggests that both the $\mathrm{T}$ allele and TT genotype were significantly associated with increased cancer risk [17]. Experimental data also support a functional role for the C-by-T substitution at the allele and homozygous genotype level $[12,28,29]$. We found that additivity was better fitted for metastasis but not to ADT resistance, even though the low number of patients carrying the TT genotype in metastasis analyses yielded a very wide $\mathrm{CI}$, hence deserving careful interpretation.

Our findings in a large cohort of patients that received ADT, support a role for HIF1a in the pathophysiology of castration resistance and the HIFlA $+1772 \mathrm{C}>\mathrm{T}$ polymorphism as a potential pharmacogenomic predictor of the response to ADT. Concordantly, a recent study demonstrated that HIF1a expression contributed both to metastasis and chemo-resistance of castration resistant prostate cancer [30]. A study comparing HIF1 A $+1772 \mathrm{C}>\mathrm{T}$ genotypes between castration-resistant $\mathrm{PCa}$ and non-cancer men showed that the T-allele was overrepresented in the cancer group, although it was not associated with survival [18]. Noteworthy, this report presents data from 196 castration-resistant

Table 4

Association of HIF1A $+1772 \mathrm{C}>\mathrm{T}$ polymorphism with resistance to ADT.

\begin{tabular}{|c|c|c|c|c|c|}
\hline & & \multicolumn{4}{|c|}{ Resistance to ADT } \\
\hline & & Univariate & & Multivariate $^{*}$ & \\
\hline$H I F 1 A+1772 \mathrm{C}>\mathrm{T}$ & LR & HR $(95 \% \mathrm{CI})$ & $p$ & $\mathrm{HR}(95 \% \mathrm{CI})$ & $p$ \\
\hline Additive model & 2.24 & & & & \\
\hline $\mathrm{CC}$ & & Referent & & Referent & \\
\hline $\mathrm{CT}$ & & $0.8(0.6-1.2)$ & 0.288 & $1.0(0.7-1.5)$ & 0.918 \\
\hline TT & & $1.8(0.7-4.6)$ & 0.183 & $6.1(2.2-17.0)$ & 0.001 \\
\hline Dominant model & 2.70 & & & & \\
\hline $\mathrm{CC}$ & & Referent & & & \\
\hline $\mathrm{T}$ carriers & & $0.9(0.6-1.2)$ & 0.460 & $1.1(0.8-1.7)$ & 0.536 \\
\hline Recessive model & 3.86 & & & & \\
\hline $\mathrm{C}$ carriers & & Referent & & Referent & \\
\hline TT & & $1.9(0.8-4.8)$ & 0.149 & $6.0(2.2-16.8)$ & 0.001 \\
\hline
\end{tabular}


Table 5

Risk for metastasis in patients receiving androgen deprivation therapy

\begin{tabular}{|c|c|c|c|c|c|c|}
\hline \multirow[b]{2}{*}{$H I F 1 A+1772 \mathrm{C}>\mathrm{T}$} & \multicolumn{3}{|c|}{ Univariate analysis ${ }^{*}$} & \multicolumn{3}{|c|}{ Multivariate analysis $^{* *}$} \\
\hline & $N$ & OR $(95 \% \mathrm{CI})$ & $p$ & $N$ & OR $(95 \% \mathrm{CI})$ & $p$ \\
\hline Additive model & 380 & & & 323 & & \\
\hline $\mathrm{CC}$ & & Referent & & & Referent & \\
\hline $\mathrm{CT}$ & & $1.7(1.0-2.7)$ & & & $1.9(1.0-3.6)$ & \\
\hline TT & & $3.5(0.6-19.4)$ & $0.055^{\mathrm{a}}$ & & $14.9(1.0-223.1)$ & $0.031^{\mathrm{a}}$ \\
\hline \multicolumn{7}{|l|}{ Dominant model } \\
\hline $\mathrm{CC}$ & & Referent & & & Referent & \\
\hline $\mathrm{T}$ carriers & 380 & $1.7(1.1-2.8)$ & 0.023 & 323 & $2.0(1.1-3.9)$ & 0.027 \\
\hline Recessive model & 380 & & & 323 & & \\
\hline $\mathrm{C}$ carriers & & Referent & & & Referent & \\
\hline $\mathrm{TT}$ & & $3.1(0.6-17.1)$ & 0.199 & & $12.9(0.9-190.1)$ & 0.063 \\
\hline
\end{tabular}

patients using univariate analysis. Another study observed a somatic rare mutation at the same locus in $1 / 15$ androgen-independent prostate tumours, whereas functional studies demonstrated in androgen-independent prostate cancer cells that the T-allele is associated with increased transcriptional activity and protein expression [28]. Therefore, we hypothesise that carrying the T-allele, which stabilises HIF1a protein and upregulates the HIFlAl gene expression, may offer a selective advantage to androgen-independent tumour cells through the upregulation of several genes involved in metastasis, angiogenesis, epithelial-to-mesenchymal transition or in other cancer-associated mechanisms [10,23,31-33]. The SNP in HIF1A at locus +1772 represents a germline variant, suggesting a cumulative impact of higher HIFla expression since birth. However, we hypothesise that $H I F 1 A+1772$ functional SNP repercussion when combined with hypoxic environmental events or with other genetic risk factors is triggered to higher extent in response to hypoxia-inductive treatments such as ADT. When confirmed in larger and independent samples, additional therapeutic schemes (such as CYP17A1 inhibitors or chemotherapy) could be offered to carriers of the poor responder TT genotype as alternative to ADT. These patients could also be enrolled in clinical trials with drugs that target HIFla function (e.g. tasquinimod and other agents that target HIFla or its downstream products) [34-37].

Present findings should be further extended and replicated by future studies focusing on genetic polymorphisms as predictors of treatment response to allow tailored therapy in PCa patients. Using this focused candidate gene approach to evaluate the HIFlA +1772 C $>$ T SNP gives us an incomplete analysis of hypoxia mechanism. Other hypoxia-related SNPs were not included in this study. However, our study has several strengths such as the selection of the candidate gene based on biological evidence of functional importance; statistical analyses accounted for relevant clinical and pathological factors. In this study all men (including the controls) were screened for prostate cancer based on both PSA level and digital rectal exam during the recruitment period and diagnosis was determined by standard biopsy or surgical sample, thus making outcome misclassification unlikely.

Our findings suggest that the HIFlA $+1772 \mathrm{C}>\mathrm{T}$ might be a useful marker of aggressive $\mathrm{PCa}$, particularly a predictor of the response to ADT, thus a plausible candidate to include in a panel of risk prediction SNPs in combination with clinical and pathologic features.

\section{Conflict of interest statement}

None declared.

\section{Acknowledgement}

Grant support: Authors acknowledge support from the Portuguese Science and Technology Foundation and Operational Programme "Factores de Competitividade (COMPETE) (PTDC/SAU-FC/71552/2006 and FCOMP-01-0124-FEDER-011113)", the Portuguese League Against Cancer - North Centre, the Calouste Gulbenkian Foundation (Oncology/2008/Project No. 96736) and from an unrestricted educational Grant for basic research in Molecular Oncology from Novartis Oncology Portugal. R.R. was the recipient of a $\mathrm{PhD}$ Grant from POPH/FSE (SFRH/BD/30021/2006) and of an International Cancer Technology Transfer Fellowship from the Union for International Cancer Control (UICC-ICRETT, ICR/10/079/2010).

\section{References}

[1] Jemal A, Bray F, Center MM, Ferlay J, Ward E, Forman D. Global cancer statistics. CA Cancer J Clin 2011;61(2):69-90.

[2] Wiklund F. Prostate cancer genomics: can we distinguish between indolent and fatal disease using genetic markers? Genome Med 2010;2(7):45.

[3] Xu J, Zheng SL, Isaacs SD, Wiley KE, Wiklund F, Sun J, et al. Inherited genetic variant predisposes to aggressive but not 
indolent prostate cancer. Proc Natl Acad Sci U S A 2010;107(5):2136-40.

[4] Teixeira AL, Ribeiro R, Cardoso D, Pinto D, Lobo F, Fraga A, et al. Genetic polymorphism in EGF is associated with prostate cancer aggressiveness and progression-free interval in androgen blockade-treated patients. Clin Cancer Res 2008;14(11):3367-71.

[5] Teixeira AL, Ribeiro R, Morais A, Lobo F, Fraga A, Pina F, et al. Combined analysis of $\mathrm{EGF}+61 \mathrm{G}>\mathrm{A}$ and $\mathrm{TGFB} 1+869 \mathrm{~T}>\mathrm{C}$ functional polymorphisms in the time to androgen independence and prostate cancer susceptibility. Pharmacogenomics J 2009;9(5):341-6.

[6] Wiklund FE, Adami HO, Zheng SL, Stattin P, Isaacs WB, Gronberg H, et al. Established prostate cancer susceptibility variants are not associated with disease outcome. Cancer Epidemiol Biomarkers Prev 2009;18(5):1659-62.

[7] Wright ME, Peters U, Gunter MJ, Moore SC, Lawson KA, Yeager M, et al. Association of variants in two vitamin e transport genes with circulating vitamin e concentrations and prostate cancer risk. Cancer Res 2009;69(4):1429-38.

[8] Swanson GP, Yu C, Kattan MW, Hermans MR. Validation of postoperative nomograms in prostate cancer patients with longterm follow-up. Urology 2011;78(1):105-9.

[9] Zheng SL, Sun J, Wiklund F, Smith S, Stattin P, Li G, et al. Cumulative association of five genetic variants with prostate cancer. N Engl J Med 2008;358(9):910-9.

[10] Fraga A, Ribeiro R, Medeiros R. Tumor hypoxia: the role of HIF. Actas Urol Esp 2009;33(9):941-51.

[11] Hill RP, Marie-Egyptienne DT, Hedley DW. Cancer stem cells, hypoxia and metastasis. Semin Radiat Oncol 2009;19(2):106-11.

[12] Tanimoto K, Yoshiga K, Eguchi H, Kaneyasu M, Ukon K, Kumazaki T, et al. Hypoxia-inducible factor-1alpha polymorphisms associated with enhanced transactivation capacity, implying clinical significance. Carcinogenesis 2003;24(11):1779-83.

[13] Semenza GL. Regulation of mammalian O2 homeostasis by hypoxia-inducible factor 1. Annu Rev Cell Dev Biol 1999;15:551-78.

[14] Smaldone MC, Maranchie JK. Clinical implications of hypoxia inducible factor in renal cell carcinoma. Urol Oncol 2009;27(3):238-45.

[15] Zhong H, De Marzo AM, Laughner E, Lim M, Hilton DA, Zagzag D, et al. Overexpression of hypoxia-inducible factor 1alpha in common human cancers and their metastases. Cancer Res 1999;59(22):5830-5.

[16] Foley R, Marignol L, Thomas AZ, Cullen IM, Perry AS, Tewari $\mathrm{P}$, et al. The HIF-1alpha C1772T polymorphism may be associated with susceptibility to clinically localised prostate cancer but not with elevated expression of hypoxic biomarkers. Cancer Biol Ther 2009;8(2):118-24.

[17] Zhao T, Lv J, Zhao J, Nzekebaloudou M. Hypoxia-inducible factor-1alpha gene polymorphisms and cancer risk: a metaanalysis. J Exp Clin Cancer Res 2009;28:159.

[18] Chau CH, Permenter MG, Steinberg SM, Retter AS, Dahut WL, Price DK, et al. Polymorphism in the hypoxia-inducible factor lalpha gene may confer susceptibility to androgen-independent prostate cancer. Cancer Biol Ther 2005;4(11):1222-5.

[19] Li H, Bubley GJ, Balk SP, Gaziano JM, Pollak M, Stampfer MJ, et al. Hypoxia-inducible factor-1alpha (HIF-1alpha) gene polymorphisms, circulating insulin-like growth factor binding protein (IGFBP)-3 levels and prostate cancer. Prostate 2007;67(12):1354-61.

[20] Mottet N, Bellmunt J, Bolla M, Joniau S, Mason M, Matveev V, et al. EAU guidelines on prostate cancer. Part II: treatment of advanced, relapsing, and castration-resistant prostate cancer. Eur Urol 2011;59(4):572-83.
[21] Scher HI, Halabi S, Tannock I, Morris M, Sternberg CN, Carducci MA, et al. Design and end points of clinical trials for patients with progressive prostate cancer and castrate levels of testosterone: recommendations of the prostate cancer clinical trials working group. J Clin Oncol 2008;26(7):1148-59.

[22] Heidenreich A, Bellmunt J, Bolla M, Joniau S, Mason M, Matveev V, et al. European association of urology. EAU guidelines on prostate cancer. Part 1: screening, diagnosis, and treatment of clinically localised disease. Eur Urol 2011;59(1):61-71.

[23] Kimbro KS, Simons JW. Hypoxia-inducible factor-1 in human breast and prostate cancer. Endocr Relat Cancer 2006;13(3):739-49.

[24] Zhong H, Semenza GL, Simons JW, De Marzo AM. Upregulation of hypoxia-inducible factor 1alpha is an early event in prostate carcinogenesis. Cancer Detect Prev 2004;28(2):88-93.

[25] Anastasiadis AG, Stisser BC, Ghafar MA, Burchardt M, Buttyan R. Tumor hypoxia and the progression of prostate cancer. Curr Urol Rep 2002;3(3):222-8.

[26] Li P, Cao Q, Shao PF, Cai HZ, Zhou H, Chen JW, et al. Genetic polymorphisms in HIF1A are associated with prostate cancer risk in a Chinese population. Asian J Androl 2012;14(6):864-9.

[27] Orr-Urtreger A, Bar-Shira A, Matzkin H, Mabjeesh NJ. The homozygous P582S mutation in the oxygen-dependent degradation domain of HIF-1 alpha is associated with increased risk for prostate cancer. Prostate 2007;67(1):8-13.

[28] Fu XS, Choi E, Bubley GJ, Balk SP. Identification of hypoxiainducible factor-1alpha (HIF-1alpha) polymorphism as a mutation in prostate cancer that prevents normoxia-induced degradation. Prostate 2005;63(3):215-21.

[29] Vainrib M, Golan M, Amir S, Dang DT, Dang LH, Bar-Shira A, et al. HIF1A C1772T polymorphism leads to HIF-1 $\alpha$ mRNA overexpression in prostate cancer patients. Cancer Biol Ther 2012;13(9):720-6.

[30] Ranasinghe WKB, Xiao L, Kovac S, Chang M, Michiels C, Bolton $\mathrm{D}$, et al. The role of hypoxia-inducible factor 1a in determining the properties of castrate-resistant prostate cancers. PLoS ONE 2013;8(1).

[31] Jeong CW, Yoon CY, Jeong SJ, Hong SK, Byun SS, Kwak C, et al. The role of hypoxia-inducible factor-1alpha and -2alpha in androgen insensitive prostate cancer cells. Urol Oncol 2013.

[32] Mathieu J, Zhang Z, Zhou W, Wang AJ, Heddleston JM, Pinna $\mathrm{CM}$, et al. HIF induces human embryonic stem cell markers in cancer cells. Cancer Res 2011;71(13):4640-52.

[33] Dai Y, Bae K, Siemann DW. Impact of hypoxia on the metastatic potential of human prostate cancer cells. Int J Radiat Oncol Biol Phys 2011;81(2):521-8.

[34] Bratt O, Häggman M, Ahlgren G, Nordle O, Björk A, Damber JE, et al. Open-label, clinical phase I studies of tasquinimod in patients with castration-resistant prostate cancer. Br J Cancer 2009;2009(101):1233-40.

[35] Pili R, Häggman M, Stadler WM, Gingrich JR, Assikis VJ, Björk A, et al. Phase II randomized, doubleblind, placebo-controlled study of tasquinimod in men with minimally symptomatic metastatic castrate-resistant prostate cancer. J Clin Oncol 2011;29:4022-8.

[36] Jennbacken K, Welén K, Olsson A, Axelsson B, Törngren M, Damber JE. Leanderson $\mathrm{T}$ Inhibition of metastasis in a castration resistant prostate cancer model by the quinoline-3carboxamide tasquinimod (ABR-215050). Prostate 2012;72(8):913-24.

[37] Liu XQ, Xiong MH, Shu XT, Tang RZ, Wang J. Therapeutic delivery of siRNA silencing HIF-1 alpha with micellar nanoparticles inhibits hypoxic tumor growth. Mol Pharm 2012:9(10):2863-74. 